\title{
Molecular and phylogenetic analysis of the porcine kobuvirus VP1 region using infected pigs from Sichuan Province, China
}

\author{
Lei Chen, Ling Zhu, Yuan-cheng Zhou, Zhi-wen Xu*, Wan-zhu Guo and Wen-yu Yang
}

\begin{abstract}
Background: Porcine kobuvirus (PKoV) is a member of the Kobuvirus genus within the Picornaviridae family. PKoV is distributed worldwide with high prevalence in clinically healthy pigs and those with diarrhea.

Methods: Fecal and intestinal samples $(n=163)$ from pig farms in Sichuan Province, China were obtained to determine the presence of PKoV using reverse transcription polymerase chain reaction assays. Specific primers were used for the amplification of the gene encoding the PKoV VP1 protein sequence. Sequence and phylogenetic analyses were conducted to clarify evolutionary relationships with other PKoV strains.

Results: Approximately 53\% (87/163) of pigs tested positive for PKoV. PKoV was widespread in asymptomatic pigs and those with diarrhea. A high prevalence of PKoV was observed in pigs younger than 4 weeks and in pigs with diarrhea. Phylogenetic analysis of 36 PKoV VP1 protein sequences showed that Sichuan PKoV strains formed four distinct clusters. Two pigs with diarrhea were found to be co-infected with multiple PKoV strains. Sequence and phylogenetic analyses revealed diversity within the same host and between different hosts. Significant recombination breakpoints were observed between the CHN/SC/31-A1 and CHN/SC/31-A3 strains in the VP1 region, which were isolated from the same sample.

Conclusion: PKoV was endemic in Sichuan Province regardless of whether pigs were healthy or suffering from diarrhea. Based on our statistical analyses, we suggest that PKoV was the likely causative agent of high-mortality diarrhea in China from 2010. For the first time, we provide evidence for the co-existence of multiple PKoV strains in one pig, and possible recombination events in the VP1 region. Our findings provide further insights into the molecular properties of PKoV, along with its epidemiology.
\end{abstract}

Keywords: Porcine kobuvirus, VP1 protein, Diarrhea, Phylogenetic analysis, Co-infection, Recombination

\section{Background}

Members of the Picornaviridae are small, non-enveloped viruses with a linear single-stranded, positive-sense RNA genome. They are a highly diverse virus family, with a number of picornaviruses known to be important pathogens of humans and other animals [1-3]. The Kobuvirus genus is relatively new within the Picornaviridae family, and kobuviruses have been detected in humans, cattle, pigs, sheep, wild boars, bats, dogs, cats, goats and rodents [2-11]. The RNA genomes of kobuviruses range

\footnotetext{
* Correspondence: abtcxzw@126.com

Animal Biotechnology Center, College of Veterinary Medicine of Sichuan Agricultural University, 46\# Xinkang Road, Yucheng District, Ya'an 625014Sichuan province, P.R. China
}

\section{Biomed Central}

from $8.2-8.4 \mathrm{~kb}$ and contain one large open reading frame (ORF) encoding a single polyprotein. This polyprotein is cleaved into structural (VP0, VP3 and VP1) and non-structural (2A, 2B, 2C, 3A, 3B and 3D) proteins [12]. Currently, the Kobuvirus genus contains two officially recognized species, Aichi virus and bovine kobuvirus, with $\mathrm{PKoV}$ a candidate species. Aichi virus strain A846/88 was first isolated in Japan, in 1991, from the fecal sample of a patient suffering acute gastroenteritis [3]. Since then, Aichi virus has been detected in the fecal samples of humans from other countries in Asia, Europe, South America and Africa [13-16], and is thought to be associated with acute gastroenteritis. Bovine kobuvirus strain U-1 was detected in culture 
medium supplemented with calf serum possibly polluted with feces, and also in fecal samples from clinically healthy Japanese cattle in 2003 [2]. Bovine kobuvirus has also been detected in asymptomatic cattle from Hungary and the Netherlands, and in cattle from Thailand and Korea suffering diarrhea [17-19]. PKoV was detected in a Hungary farm in early 2007 and the complete genome (strain swine/S-1-HUN/2007/Hungary) characterized [4]. Since it was first identified, PKoV has been detected in China, Thailand, Spain, Japan, Korea, the United States, Brazil, the Netherlands, and recently in the Czech Republic [19-26]. The prevalence of PKoVpositive fecal samples ranged from 16.7-99\% worldwide. On a single farm in Hungary, the prevalence among clinically healthy domestic pigs was 65\% (39/60) and $53.3 \%(32 / 60)$ for 2007 and 2008, respectively [27]. In northern Spain, the rate of detection for PKoV was $48.7 \%$ in 2011 [22]. Epidemiological research of $\mathrm{PKoV}$ infection in Thailand revealed that 99\% (97/98) of samples examined between 2001-2003 [21], and 97\% $(127 / 131)$ of samples from pigs suffering diarrhea between 2006-2008, were positive for the virus [28]. In healthy pigs from Japan, 45.4\% (133/293) were positive for $\mathrm{PKoV}$ in 2010 [23]. Analysis of samples taken from eight Korean provinces showed that $84.5 \%$ (71/84) and $19.3 \%(16 / 83)$ of samples from pigs with or without diarrhea were positive for PKoV in 2010 [29]. Also in 2010, PKoV was reported in $45.5 \%(15 / 33)$ and $32.6 \%(28 / 86)$ of non-diarrheal and diarrheal samples, respectively from three Korean provinces [24]. In Brazil and the Netherlands, prevalence was reportedly $53 \%(61 / 115)$ and $16.7 \%(3 / 18)$, respectively [19]. On USA farms, PKoV infection rates were $21.9 \%(25 / 114)$ in pigs with diarrhea and $21.7 \%$ (10/46) for apparently healthy pigs [25]. For healthy pigs from the Czech Republic, the overall prevalence was $87.2 \%$ (171/196) [26]. In China, PKoV was detected in $38.8 \%$ $(45 / 116)$ and $30.12 \%(97 / 322)$ of samples from Shanghai and Lulong County, respectively [30,31].

$\mathrm{PKoV}$ is an emerging virus prevalent worldwide in healthy pigs, and in pigs with diarrhea. The pathogenicity of $\mathrm{PKoV}$ remains unclear as culturing of the virus in vitro has not been successful. A recent study from Korea suggested that PKoV might be the etiological agent of gastroenteritis in pigs [29]. Most molecular epidemiological investigations of $\mathrm{PKoV}$ have focused on the $3 \mathrm{D}$ region, while information regarding the molecular properties of the gene encoding the VP1 protein is relatively limited. The VP1 region is the most exposed and immunodominant portion of the capsid protein, and is the most variable structural protein among all kobuviruses [2,32]. It plays an important role in the molecular epidemiology and genetic evolution of kobuviruses. Yu et al. identified $11 \mathrm{PKoV}$ VP1 sequences in piglets, from Lulong County China, younger than
15 days; similarities among these sequences ranged from 86.7-100\% [30]. Okitsu et al. described the genetic diversity of PKoV VP1 in Japan and Thailand [28]. Recently VP1 protein sequences were used to investigate the relatedness among PKoV strains by Shi et al.; their findings indicated that known $\mathrm{PKoV}$ strains form four distinct lineages [33].

Further epidemiological and molecular research on $\mathrm{PKoV}$ strains are required to assist researchers and health officials to identify its epidemic characteristics, distribution, evolutionary features and genome sequences. The aim of our study was to determine the prevalence of $\mathrm{PKoV}$ in Sichuan Province China, and to analyze the phylogenetic and genetic relationships of the VP1 region between Sichuan PKoV and reference kobuvirus strains. Statistical analysis was also conducted to determine any association between $\mathrm{PKoV}$ infection and the age of pigs, or symptoms of diarrhea.

\section{Results}

\section{Prevalence of PKoV in pigs of Sichuan Province}

Using primers targeting the 3D region, 53.4\% (87/163) pigs were positive for PKoV. The proportion of asymptomatic pigs and those with diarrhea that were PKoVpositive were $29.4 \%(15 / 51)$ and $64.3 \%$ (72/112), respectively. For the samples from pigs with diarrhea, $76.5 \%$ (52/68) were from suckling pigs, $46.7 \%(7 / 15)$ were from weaned pigs, $30 \%$ (3/10) were from growing/ finishing pigs, and $52.6 \%(10 / 19)$ were from sows. Among the PKoV-positive clinically healthy pigs, $40 \%$ (10/25), 25\% (2/8), $14.3 \%(1 / 7)$, and $18.2 \%$ (2/11) were suckling pigs, weaned pigs, growing/finishing pigs, and sows, respectively (Table 1). PKoV was detected in 17 of the 18 cities sampled. None of the fecal samples from apparently healthy Tibetan pigs were positive for PKoV. Statistical analysis showed that porcine kobuvirus infection strongly correlated with suckling pigs, which were younger than 4 weeks old $\left(\chi^{2}=10.941, p=9.4 \times 10^{-4}\right)$. PKoV infection was significantly associated with diarrhea in pigs $\left(\chi^{2}=17.126, p=3.5 \times 10^{-5}\right)$ using Pearson's chi-square test.

\section{Sequence and phylogenetic analysis}

Among the 87 PKoV-positive samples, 32 were randomly selected for amplification of the gene encoding the VP1 protein. We obtained 30 partial PKoV VP1 sequences using a nested PCR technique. Nucleotide and deduced amino acid similarities among these 30 partial sequences ranged from $82-100 \%$ and $86.9-100 \%$, respectively. We detected multiple strains of $\mathrm{PKoV}$ in two samples (pigs 31 and 32) following sequence examination of first-round PCR amplicons. We detected three PKoV strains within pig 31, based on the presence of three different $1190 \mathrm{bp}$ fragments, designated A1, A2, 
Table 1 Prevalence of Porcine kobuvirus in pigs from Sichuan Province

\begin{tabular}{|c|c|c|c|}
\hline Pig age & Diarrheic pigs & Non-diarrheic pigs & Total \\
\hline Suckling pigs & $52 / 68^{\mathrm{a}}(76.5 \%)$ & 10/25(40.0\%) & 62/93(66.7\%) \\
\hline \multicolumn{4}{|l|}{ (<4 weeks, $n=93$ ) } \\
\hline Weaned pigs & 7/15(46.7\%) & $2 / 8(25 \%)$ & 9/23(39.1\%) \\
\hline \multicolumn{4}{|l|}{$(<7$ weeks, $n=23$ ) } \\
\hline Growing/finisher pigs & 3/10(30.0\%) & $1 / 7(14.3 \%)$ & 4/17(23.5\%) \\
\hline \multicolumn{4}{|l|}{ ( $<6$ months, $\mathrm{n}=17$ ) } \\
\hline Sows & 10/19(52.6\%) & $2 / 11(18.2 \%)$ & $12 / 30(40.0 \%)$ \\
\hline \multicolumn{4}{|l|}{$(>1$ year, $\mathrm{n}=30)$} \\
\hline Total $(n=163)$ & 72/112(64.3\%) & 15/51(29.4\%) & 87/163(53.4\%) \\
\hline
\end{tabular}

${ }^{a}$ Number of porcine kobuvirus RNA positive samples/tested samples.

and A3. The nucleotide and deduced amino acid identities ranged from $97.5-98.8 \%$ and $98.2-98.7 \%$, respectively. The $1190 \mathrm{bp}$ fragment covered the full VP1 region (nt 182-943), a portion of VP3 (nt 1-181), and a part of the $2 \mathrm{~A}$ region (nt 944-1190). For pig 32, sequencing results revealed two different PKoV strains, designated B1 and B2. Sequence analysis revealed that B1 and B2 were significantly diverse at the genetic level with $84.5 \%$ and $90.7 \%$ identity at the nucleotide and amino acid level, respectively. We submitted these 35 PKoV VP1 gene sequences that were analyzed to GenBank (Accession numbers: KF157917-KF157951).

A phylogenetic tree was generated using the 35 sequences we determined. In several genera of the Picornaviridae, similarities at the nucleotide and amino acid level for VP1 are used as criteria for taxonomic classification. The phylogenetic tree indicated that the 35 sequences we submitted to GenBank were indeed PKoV strains (Figure 1). A neighbor-joining tree based on the VP1 gene indicated that the 35 Sichuan PKoV strains could be divided into four large clusters (Clusters A, B, C, and D) (Figure 1). JX294863 (CHN/2012a) was a PKoV VP1 sequence we submitted to GenBank in 2012, which was also isolated from Sichuan Province. Most Sichuan strains (30/36) were located in Cluster A, along with $\mathrm{PKoV}$ reference strains from China, the United States, Japan, and Thailand. Cluster A could be divided further into five subgroups: 11 VP1 sequences from China along with those for CHN/2012a and CHN/ SC/32-B2 formed subgroup 1. Nucleotide identities within subgroup 1 were $84.7-100 \%$, while amino acid similarities were $92.2-100 \%$. Subgroup 2 comprised $\mathrm{CHN} / \mathrm{SC} / 30$ only, while subgroup 3 contained CHN/SC/ 16, CHN/SC/18, two Chinese PKoV VP1 sequences, H15/2012/USA and PKoVs from Thailand and Japan. $\mathrm{CHN} / \mathrm{SC} / 06$ clustered into subgroup 4 and was closely related to CMP02/08-THA, and subgroup 5 was made up of 24 Sichuan strains. Within subgroup 5, these VP1 sequences were $97-100 \%$ similar at the nucleotide level, and $95.4-100 \%$ similar at the amino acid level. CHN/ SC/13 was highly similar to PKoV strains previously discovered in the United States and in Cluster B, sharing $85.6 \%$ and $87.3 \%$ nucleotide identity with H21/2012/ USA and H17/2012/USA, respectively and greater than 95\% identity with the deduced amino acid sequences. $\mathrm{CHN} / \mathrm{SC} / 11$ and $\mathrm{CHN} / \mathrm{SC} / 10$ were closely grouped together in Cluster $\mathrm{C}$, along with the $\mathrm{PKoV}$ isolate $\mathrm{XC}$ from China. $\mathrm{CHN} / \mathrm{SC} / 11$ and $\mathrm{CHN} / \mathrm{SC} / 10$ sequences were compared with that for the $\mathrm{XC}$ isolate and found to be $86.2 \%$ and $84.2 \%$ similar, respectively, at the nucleotide level; amino acid identities were $94.5 \%$ and 92.2\% similar, respectively. For Cluster $\mathrm{D}, \mathrm{CHN} / \mathrm{SC} / 12$, $\mathrm{CHN} / \mathrm{SC} / 24$ and $\mathrm{CHN} / \mathrm{SC} / 32-\mathrm{B} 1$ clustered with the $\mathrm{PKoV}$ reference strains from China (isolate $\mathrm{XX}, \mathrm{SH}-\mathrm{W}$ /CHN/2010/China, and CH/HNXX-4/2012).

CHN/SC/31-A1 (KF157947),CHN/SC/31-A2 (KF1579 48), and $\mathrm{CHN} / \mathrm{SC} / 31-\mathrm{A} 3(\mathrm{KF} 157949)$, which were isolated from pig 31, formed a single cluster (Figure 1), whereas, CHN/SC/32-B1 (KF157950) and CHN/SC/32B2 (KF157951) were in two distinct groups. The five 1190-bp polyprotein sequences were compared with the corresponding region in eight complete PKoV sequences. Nucleotide and amino acid similarities ranged from $82.1-88 \%$ and $88.9-95.7 \%$, respectively (Table 2 ).

\section{Recombination analysis}

Significant recombination breakpoints were detected for different polyprotein gene sequences isolated from the same host using sequence alignment and software analyses. We observed recombination events in the three polyprotein sequences from pig 31 using the Recombination Detection Program (RDP) and its automated suite of algorithms, including GENECONV, MaxChi, Chimaera, SiScan and BootScan [34-38]. At least four sequences were required to run the Simplot program [39]. On the basis of the RDP analysis results, both CHN/SC/31-A1 and CHN/SC/31-A3 were identified as the putative parental strains, $\mathrm{CHN} / \mathrm{SC} / 31-\mathrm{A} 2$ was a 


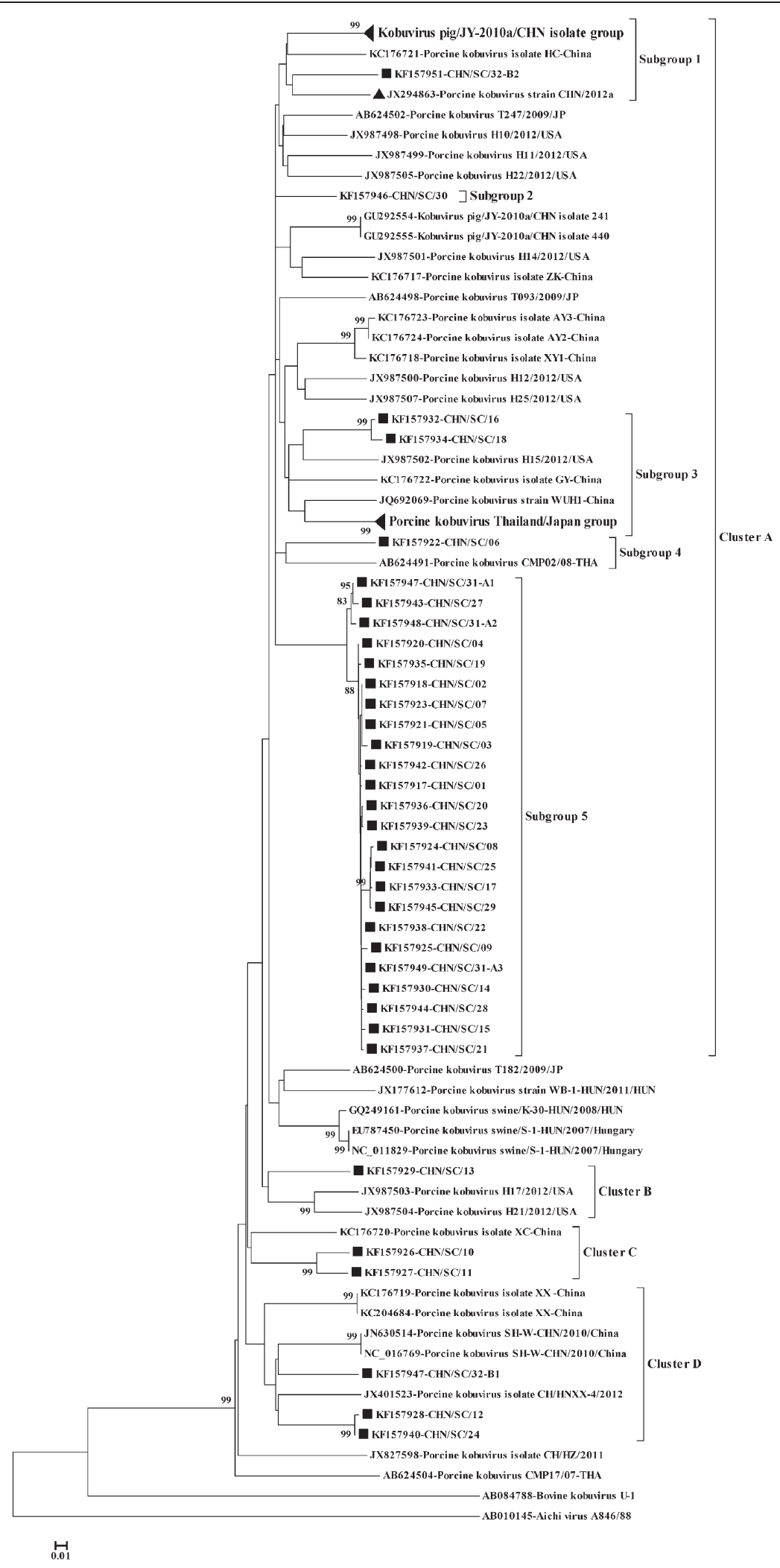

Figure 1 (See legend on next page.) 
(See figure on previous page.)

Figure 1 Phylogenetic analysis of PKoV VP1 protein sequences detected in Sichuan province. The phelogenetic tree was constructed using the neighbor-joining method, Kimura 2-parameter model by MEGA version 5.0. Bootstrap values (based on 1,000 replicates) >75\% are shown. Filled quadrate $(\mathbf{-})$ indicates PKoV VP1 protein sequences obtained in this study. Filled triangle $(\mathbf{\Lambda})$ represents a Sichuan strain PKoV VP1 protein sequence has been reported in our previous study. Kobuvirus pig/JY-2010a/CHN isolate group contained 10 sequences from China forming a tight cluster. The Genbank accession numbers are: GU292548-GU292553, GU292556-GU292559; PKoV Thailand/Japan isolate group including 10 sequences clustered in a monophyletic branch. Their accession numbers in Genbak are as follows: AB624490, AB624492-AB624497, AB624499, AB624501, AB624503.

possible recombinant strain, and $\mathrm{CHN} / \mathrm{SC} / 32-\mathrm{B} 2$ was regarded as an outgroup. The Simplot analysis results confirmed possible recombination events among the different polyprotein sequences from pig 31 . The similarity plot (Figure 2) displays consecutive nucleotide identities between the queried and parental strains. The recombined $\mathrm{CHN} / \mathrm{SC} / 31-\mathrm{A} 2$ strain exhibited greater similarity to $\mathrm{CHN} / \mathrm{SC} / 31-\mathrm{A} 1$ upstream of nt 588 , but shared higher sequence similarity with $\mathrm{CHN} / \mathrm{SC} / 31-\mathrm{A} 3$ downstream of nt 809 (Figure 2). Between nucleotides 588 and 809, we observed crossovers sites for the two putative parental sequences. Essentially, the parental sequences shared equal identity to the query strain, and we postulated that these were the sites of recombination. BootScan analysis showed potential recombination breakpoints between nt 609-835 (Figure 3). Before the first breakpoint, near nt 609, high bootstrap values for clustering of $\mathrm{CHN} / \mathrm{SC} / 31$-A 1 with $\mathrm{CHN} / \mathrm{SC} / 31$-A2 were observed. In contrast, after the last breakpoint, near nt 835, CHN/SC/31-A2 clustered more closely with CHN/ $\mathrm{SC} / 31-\mathrm{A} 3$. Some changes that affected clustering between nt 609-835 were observed, with nt 609-635 and 676-759 of $\mathrm{CHN} / \mathrm{SC} / 31-\mathrm{A} 2$ more closely related to CHN/SC/31-A3, while nt 635-676 and 759-835 of $\mathrm{CHN} / \mathrm{SC} / 31-\mathrm{A} 2$ were more likely to cluster with $\mathrm{CHN} /$ $\mathrm{SC} / 31-\mathrm{A} 1$. These results were in accordance with the results from the quick trees generated by Simplot.

\section{Discussion}

Our findings indicate that $\mathrm{PKoV}$-infected pigs are not restricted geographically but distributed worldwide regardless of clinical conditions. In the present study, we determined $\mathrm{PKoV}$ infection status and prevalence in healthy pigs and in those suffering diarrhea from Sichuan Province, China. PKoV was detected in $17 / 18$ sampled cities. Around 53\% (87/163) of samples contained PKoV, with $64.3 \%$ (72/112) of diarrhea samples and $29.4 \%(15 / 51)$ of normal samples containing the virus. These results indicate general circulation and endemic infection of $\mathrm{PKoV}$ in Sichuan domestic pigs. We also confirmed that $\mathrm{PKoV}$ is common in apparently healthy pigs, which agrees with the findings presented by researchers in other countries. The infection rate in healthy pigs $(29.4 \%)$ was similar to that seen in Lulong County (30.12\%), slightly higher than that for Shanghai
(22.4\%) [31], and the United States (21.7\%) [25], and much lower than that for Hungary (65\%) [27]. In pigs with diarrhea, prevalence was $64.3 \%$ and in accordance with that previously reported in Shanghai (61.2\%) [31], and much lower than that observed in Thailand (9799\%) [21,28], Brazil (78.4\%) [19] and Korea (84.5\%) [29]. These differences in prevalence can be largely attributed to sampling time, sampling range, fecal consistency, and age of evaluated pigs.

Statistical analysis of $\mathrm{PKoV}$ incidence suggests that PKoV infection correlates with diarrhea $\left(\chi^{2}=17.126\right.$, $\left.p=3.5 \times 10^{-5}\right)$. Similar results have been reported in Shanghai $(p=0.000)$, Brazil $(p=0.0002)$ and Korea $(p=$ $\left.3.2 \times 10^{-17}\right)$ using Pearson's chi-square test $[19,29,31]$. However, it was not possible to conclusively show that PKoV was the etiological agent of diarrhea. The existence of other pathogens that can cause diarrhea could not be ruled out. In three diarrhea samples from Korea that tested positive for $\mathrm{PKoV}$, other enteric pathogens were not detected [29]. There was a high prevalence of virus in pigs with diarrhea from Thailand (97-99\%) [21,28] and Korea (84.5\%) [29]. These observations imply that PKoV might have some association with diarrhea in pigs. The lack of a cell culture system to propagate $\mathrm{PKoV}$ in vitro limits further study regarding the biology and pathogenicity of this emerging virus.

Among the four tested age groups, piglets under the age of 4 weeks were more likely to be infected with PKoV $\left(\chi^{2}=10.941, p=9.4 \times 10^{-4}\right)$, which is similar to what has been reported in Hungary, Shanghai, the United States and Brazil. These reports indicate that young piglets are highly susceptible to PKoV infection [19,25,27,31]. A study conducted by Barry et al. indicated that this might be possibly be due to an inefficient immune response or other intrinsic age-related factors [19].

Prevalence of PKoV in suckling, weaned, and growing/ finisher pigs decreased as host age increased. Similar patterns have been observed in swine herds from Hungary, Korea, the United States, Brazil, and Japan [23-25,27,29]. In the Czech Republic, higher PKoV prevalence in samples from post-weaning pigs and nursing piglets were seen compared with those obtained from an abattoir [26]. Therefore, PKoV infection might have an association with host age. Further epidemiological studies from other geographical areas will be required to clarify this. 
Table 2 Nucleotide and amino acid identities of the polyprotein gene sequences

\begin{tabular}{|c|c|c|c|c|c|c|c|c|c|c|c|c|c|}
\hline \multirow[t]{2}{*}{ Strain } & \multicolumn{13}{|c|}{ Nucleotide identity (\%) } \\
\hline & $\mathrm{CHN} / \mathrm{SC} / 31$ & $\mathrm{CHN} / \mathrm{SC} / 32$ & $\mathrm{CHN} / \mathrm{SC} / 33$ & $\mathrm{CHN} / \mathrm{SC} / 34$ & $\mathrm{CHN} / \mathrm{SC} / 35$ & S-1-HUN & $\mathrm{Y}-1-\mathrm{CHI}$ & SH-W-CHN & WUH1 & WB-1-HUN & HNXX-4 & $\mathrm{CH} / \mathrm{HZ} / 2011$ & $x x$ \\
\hline $\mathrm{CHN} / \mathrm{SC} / 31$ & - & 98.3 & 97.5 & 85.1 & 86.7 & 87.8 & 87.8 & 84.4 & 86.1 & 84.7 & 85.2 & 82.8 & 84.0 \\
\hline $\mathrm{CHN} / \mathrm{SC} / 32$ & 98.7 & - & 98.8 & 85.3 & 86.8 & 87.4 & 87.3 & 84.4 & 86.3 & 84.7 & 85.1 & 82.1 & 84.0 \\
\hline $\mathrm{CHN} / \mathrm{SC} / 33$ & 98.2 & 98.7 & - & 85.7 & 87.3 & 87.2 & 87.6 & 84.4 & 86.5 & 84.8 & 85.3 & 82.5 & 84.4 \\
\hline $\mathrm{CHN} / \mathrm{SC} / 34$ & 91.9 & 91.7 & 92.4 & - & 84.5 & 84.5 & 85.4 & 87.9 & 84.5 & 83.6 & 88.0 & 83.4 & 86.9 \\
\hline CHN/SC/35 & 95.7 & 95.2 & 95.5 & 90.7 & - & 87.2 & 87.9 & 84.5 & 86.3 & 85.1 & 83.4 & 82.2 & 83.7 \\
\hline S-1-HUN & 95.7 & 95.7 & 95.5 & 91.4 & 95.5 & - & 86.0 & 84.3 & 86.9 & 86.6 & 83.4 & 84.4 & 84.8 \\
\hline $\mathrm{Y}-1-\mathrm{CHI}$ & 94.2 & 94.2 & 94.2 & 92.2 & 95.7 & 94.9 & - & 86.2 & 87.3 & 84.4 & 84.8 & 83.3 & 84.4 \\
\hline $\mathrm{SH}-\mathrm{W}-\mathrm{CHN}$ & 89.9 & 89.6 & 89.9 & 93.9 & 88.9 & 88.6 & 89.6 & - & 84.5 & 82.8 & 86.5 & 84.0 & 86.4 \\
\hline WUH1 & 95.7 & 95.5 & 95.2 & 91.4 & 93.7 & 96.0 & 93.9 & 89.1 & - & 85.1 & 84.2 & 83.4 & 85.5 \\
\hline WB-1-HUN & 92.4 & 92.2 & 91.9 & 89.9 & 90.7 & 93.4 & 91.9 & 87.1 & 93.7 & - & 83.0 & 81.1 & 84.5 \\
\hline HNXX-4 & 91.2 & 90.9 & 91.4 & 96.5 & 89.9 & 90.9 & 91.4 & 92.7 & 90.7 & 90.4 & - & 83.5 & 87.7 \\
\hline $\mathrm{CH} / \mathrm{HZ} / 2011$ & 90.9 & 90.7 & 91.2 & 92.7 & 90.4 & 90.7 & 91.9 & 90.9 & 90.9 & 89.1 & 91.7 & - & 83.9 \\
\hline$X X$ & 90.4 & 90.2 & 90.4 & 94.4 & 88.9 & 90.2 & 89.9 & 91.9 & 91.7 & 90.2 & 93.9 & 90.9 & - \\
\hline & & & & & $\mathrm{Am}$ & o identity (\% & & & & & & & \\
\hline
\end{tabular}

The reference porcine kobuvirus used in the comparison and their accession numbers are as follows: S-1-HUN (EU787450), Y-1-CHI (GU292559), SH-W-CHN (JN630514), WUH1 (JQ692069), WB-1-HUN (JX177612), HNXX4 (JX401523), CH/HZ/2011 (JX827598), XX (KC204684). 


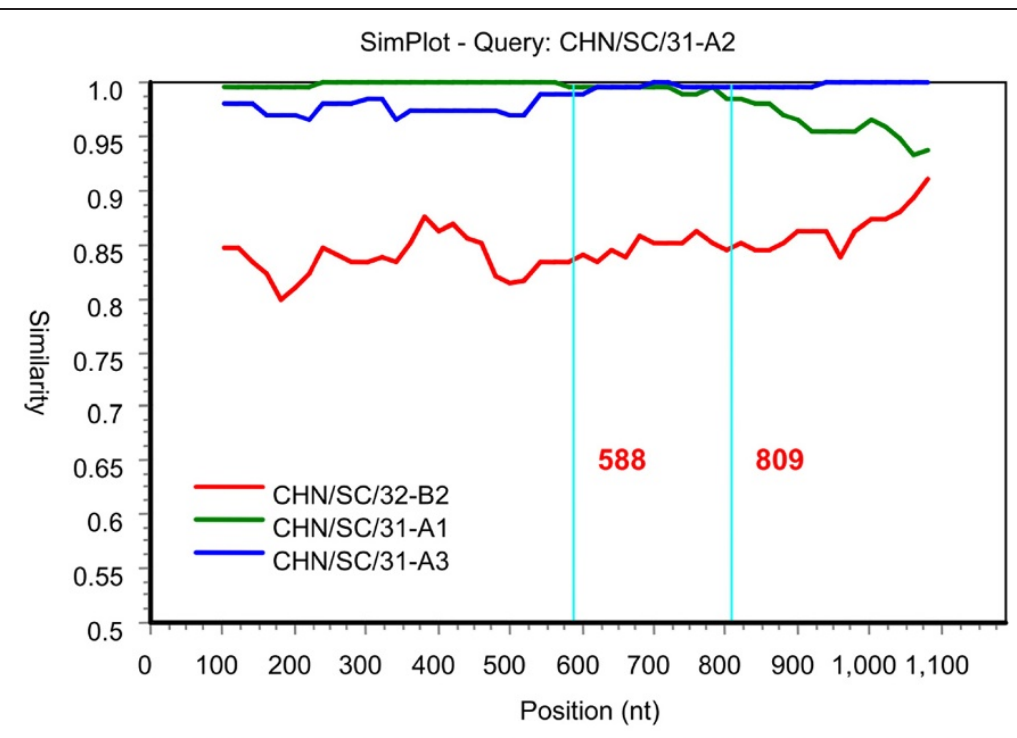

Figure 2 Nucleotide similarity comparison between the putative parental strains and the possible recombination strain. CHN/SC/31-A1 and $\mathrm{CHN} / \mathrm{SC} / 31-\mathrm{A} 3$ were the putative parental strains, and $\mathrm{CHN} / \mathrm{SC} / 31-\mathrm{A} 2$ was the query sequence, $\mathrm{CHN} / \mathrm{SC} / 32-\mathrm{B} 2$ was an outgroup. The $\mathrm{X}$-axis indicates nucleotide positions, and the $y$-axis shows similarity.

The overall frequency $(40.0 \%)$ of $\mathrm{PKoV}$ in sows is much lower than that reported by Dufkova et al. (90.9\%), but much higher than that reported by Barry et al. $(11.8 \%)$ [19,26]. According to these researchers, unproductive infection and passive shedding of the virus might result in the low prevalence among sows living in the same breeding environment. However, these conditions can lead to a high prevalence in piglets, as infected sows might act as a reservoir of PKoV and cause continuous infection of piglets.
Kobuvirus was not detected in any of the Tibetan pigs we sampled. It is possible that $\mathrm{PKoV}$ infection is not as frequent in Tibetan pigs compared with that observed in domestic pigs. However, as only four pigs were examined it is more likely that this number is not representative of the actual infection status.

The VP1 sequences identified in Sichuan Province formed four large clusters, suggesting multiple PKoV strains are circulating in Sichuan Province. Previous studies have already revealed the existence of multiple

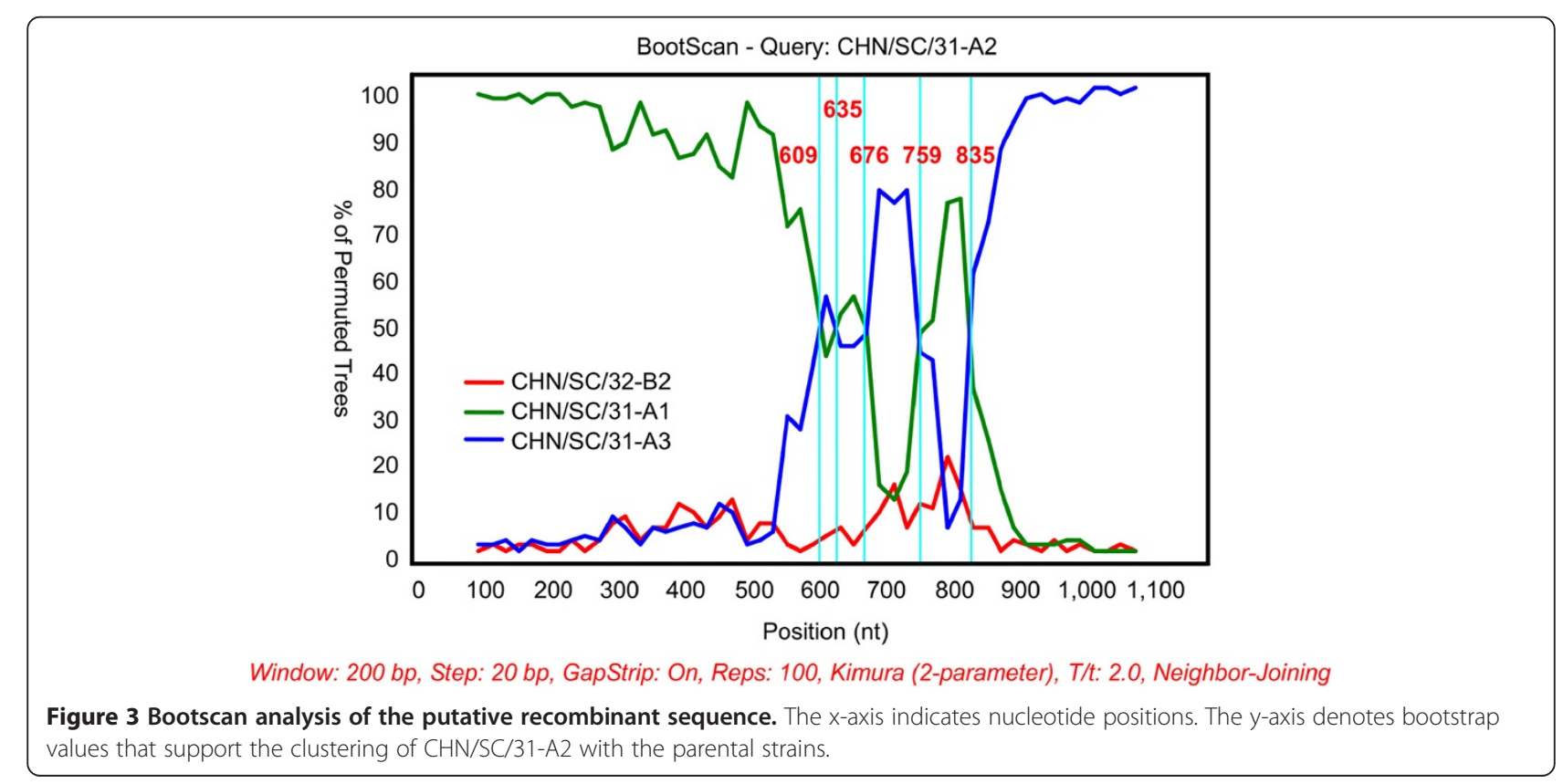


PKoV lineages in China and Korea [21,24,31]. Our phylogenetic analyses confirmed high levels of genetic diversity for the VP1 gene, which has been previously reported $[28,32,40]$.

We found that two pigs (pigs 31 and 32) were coinfected with multiple PKoV strains. Three different PKoV strains were found in pig 31, and two different PKoV strains in pig 32. This is the first report, with supporting evidence, of multiple strains of PKoV coinfecting a single pig. On a Brazilian farm, different PKoV strains were suspected to exist in a serum sample from an individual pig, but only one strain was detected. Identification of the strain was based on a gene that was more conserved than that for VP1. The authors of this report suggested it was likely that there were indeed two different strains and those they were not only a result of constant changes in the RNA genome of kobuviruses [19]. CHN/SC/31-A1, CHN/SC/31-A2 and CHN/SC/31A3 (obtained from pig 31) formed a cluster. CHN/SC/ 32-B1 and CHN/SC/32-B2 belonged to different branches, sharing $84.5 \%$ nucleotide sequence identity. This would suggest genetic diversity of PKoV within the same host and between different hosts. This is also the first report describing marked sequence diversity of $\mathrm{PKoV}$ within the same host.

Recombination plays an important role in the evolution of virus genomes. It is a major driving force for the generation of new genotypes or strains of virus. Significant recombination breakpoints were observed in the polyprotein gene sequences for pig 31. Two parent strains simultaneously infecting one host is a prerequisite for recombination. Co-infection of multiple PKoV strains in the same pig may potentially facilitates the occurrence of recombination events. Possible recombination events were analyzed for $\mathrm{CHN} / \mathrm{SC} / 31-\mathrm{A} 2$; these might have been generated from recombination between $\mathrm{CHN} / \mathrm{SC} / 31-\mathrm{A} 1$ and $\mathrm{CHN} / \mathrm{SC} / 31-\mathrm{A} 3$ in the VP1 region. Recombination events have contributed to the genetic diversity within hosts that we observed. Multiple PKoV strains in the same pig could have arisen from recombination events [41].

Wang et al. used Simplot for genetic analysis of PKoV strains; however, no significant recombination events were identified in SH-W-CHN, the strain they investigated. Certain possible recombination signals were identified in a small region (nt 8083-8210) at the 3' end of the viral genome [31]. BootScan results and phylogenetic analysis of five complete Aichi virus sequences revealed a mosaic genome sequence of Aichi virus [42]. Phylogenetic analysis of the VP1 region and 3D region of strain H023/2009/JP suggest it may be a natural recombinant from porcine and bovine kobuviruses [23,28]. Recombination in kobuviruses is likely to be a usual phenomenon, just as it is in other members of the Picornavirus genus [43].
PKoV infection is widely distributed in healthy pigs and asymptomatic pigs, providing favorable conditions for recombination [31]. The pathogenic and zoonotic potential of $\mathrm{PKoV}$ remains unclear. The closely related Aichi virus is the causative agent of human gastroenteritis, and bovine kobuvirus is associated with diarrhea in cattle $[3,12,17,44-46]$. It would appear that the pathogenesis of $\mathrm{PKoV}$ is similar to that for other picornaviruses, and we believe that it may have a major role in causing enteric diseases in swine.

Since the end of 2010, massive outbreaks of diarrhea have occurred in suckling piglets in China; however, the etiological agent has yet to be determined. Affected pigs exhibited signs of watery diarrhea, dehydration, and vomiting with morbidity ranging $80-100 \%$ and mortality between $50-90 \%$. Of the suckling pigs we tested in this study, $76.5 \%(52 / 68)$ were suffering from diarrhea and positive for PKoV. A high frequency of $\mathrm{PKoV}$ in piglets with gastroenteritis has been observed in other countries. Therefore, we propose that PKoV is the likely etiological agent of these outbreaks of severe diarrhea in China that began in 2010.

Recombination in kobuviruses creates changes in virus genomes, which probably generates new virus variants. Cao et al. sequenced and analyzed the complete genome of a PKoV variant with a 30 -amino acid deletion in the $2 \mathrm{~B}$-coding region and a threonine amino acid insertion in its VP1 region. This variant was isolated from the 2010 outbreak in China [47]. It is possible that PKoV variants generated through recombination or other evolutionary forces are related to the large-scale outbreak of severe diarrhea in suckling piglets from Sichuan Province. Further research is required to determine the exact role of PKoV variants in swine disease.

Many emerging viruses are of zoonotic origin and cause epidemics in humans after overcoming the interspecies barrier through mutation or recombination events. Intertypic recombination in H023/2009/JP implies the possibility of cross-species transmission of kobuviruses $[23,28]$. PKoV was not detected among 454 samples that were obtained from children with diarrhea in China [30]. Given that the frequency of recombination events in RNA viruses is relatively high, the possibility of zoonotic transmission among kobuvirus cannot be excluded.

PKoV is prevalent in both healthy and diseased pigs, and we suspect that at least two different PKoV types exist in piggeries. One type likely leads to gastroenteritis in pigs and possibly acts in combination with other enteric viruses; the other type probably causes subclinical infections in animals. Similar speculation has been mentioned by Verma et al. They also speculated that PKoV pathogenicity could be related to virus load and the presence of other enteric viruses, or kobuvirus might 
just be an endogenous passenger virus [25]. The difficulties in propagating $\mathrm{PKoV}$ in vitro limit our understanding of the growth kinetics and pathogenicity of this virus. Detection of PKoV in serum samples has been reported in Hungary and Brazil [19,27]. Further extensive epidemiological investigation of different PKoV strains from various regions would facilitate the understanding of its clinical and epidemiological characteristics.

\section{Conclusions}

In conclusion, $\mathrm{PKoV}$ is endemic to Sichuan Province regardless of clinical conditions. High prevalence of this virus in piglets under the age of 4 weeks, and in pigs with diarrhea was observed. Genetic diversity of the virus within the same host and between different hosts was seen. For the first time, we provide evidence of $\mathrm{PKoV}$ recombination in the VP1 region, along with the existence of multiple PKoV strains in a single pig. These findings should contribute to understanding features of PKoV epidemics and genetic characteristics of the virus. Greater attention should be paid to this potential pathogen, and PKoV should be routinely tested for in diarrhea samples sent to diagnostic laboratories.

\section{Methods}

\section{Specimens}

A total of 163 porcine intestinal and fecal samples were collected during 2011-2012, covering 18/21 cities of Sichuan Province, China. The number of non-diarrheal and diarrheal stool was 51 and 112, respectively. In addition, 4 fecal specimens were obtained from apparently healthy Tibetan pigs in Kangding County, Ganzi Tibetan Autonomous Prefecture. The collections consisted of 93 samples from suckling pigs (< 4 weeks), 23 samples from weaned pigs ( $<7$ weeks), 17 samples from growing/finisher pigs (< 6 months), 30 samples from sows (> 1 year). One sample was obtained per pig and placed into a sterile specimen container. Of note, sampling procedures were approved by the National Institute of Animal Health Animal Care and Use Committee of Sichuan Agricultural University Ethics Committee (approval number 2010-020).

\section{RNA extraction and reverse transcription-PCR (RT-PCR)}

Intestinal contents and fecal samples were prepared as $10 \%(\mathrm{wt} / \mathrm{vol})$ intestinal/fecal suspensions with phosphate-buffered saline (PBS, $\mathrm{pH}$ 7.2-7.4) through vortex. The prepared sample suspensions were clarified by centrifugation (4000 r.p.m, $10 \mathrm{~min}, 4^{\circ} \mathrm{C}$ ). Total RNA was extracted from a $300 \mu \mathrm{l}$ starting volume of the centrifuged sample suspensions using TRIZOL reagent (TaKaRa Bio Dalian, CO., LTD.) according to the manufacturer's instructions. The extracted RNA was resuspended in $30 \mu \mathrm{l}$ RNAase-free water. Reverse transcription was carried out using a cDNA synthesis kit (TaKaRa Bio Dalian, CO., LTD.), and the cDNA was immediately used for amplification or stored at $-40^{\circ} \mathrm{C}$.

PKoV screening was assessed by amplifying a 495-bp fragment using previously reported primers specific for the $3 \mathrm{D}$ region of PKoV [20]: forward:5' -TGGACGACC AGCTCTTCCTTAAACAC-3', reverse:5' -AGTGCAAG TGCAAGTCTGGGTTGCAGCCAACA-3'; Amplicons were visualized on a $1.5 \%$ ethidium-bromide-stained agarose gel under ultraviolet transillumination. Negative controls were analyzed in parallel with each primer set to discard contaminations and false positive.

\section{Polyprotein gene amplification and sequencing}

Representative PKoV positive strains detected in this study were randomly selected for analyzing their VP1 sequences. A nested PCR was performed to amplify the VP1 region. Amplification of the PKoV VP1 partial sequence was conducted by using forward primer $5^{\prime}$ GTGGTATCCAAGCTCCTGGATTTC-3' and reverse

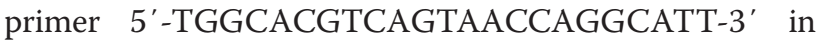
the first-round PCR and forward primer $5^{\prime}$-GTCTCC AGCATTGAGTCTGG-3' and reverse primer 5' - AGG GCGGACCACAGCAGCAACA-3' in the nested PCR. The first-round PCR was aimed to amplify the PKoV polyprotein sequence, covered the full VP1 region, a portion of VP3, and a part of the $2 \mathrm{~A}$ region. The nested PCR was designed to amplify the partial VP1 sequence, the amplicon size is about $706 \mathrm{bp}$.

The PCR was carried out by using PrimeSTAR Premix (TaKaRa Bio Dalian, CO., LTD.) containing high fidelity Taq DNA polymerase. After nested PCR, the reaction mixture was added with Taq polymerase (TaKaRa Bio Dalian, CO., LTD.) and incubated at $72^{\circ} \mathrm{C}$ for $30 \mathrm{~min}$. In this way, deoxyadenosines could be added to $3^{\prime}$ end of the PCR products. PCR products were purified and cloned into the pMD-T-19 simple vector (TaKaRa Bio Dalian, CO., LTD.) prior to sequencing. Three clones were sequenced per sample.

First-round PCR products were directly subjected to sequencing in Sangon Biotech with primers used in the first-round PCR when strong target bands could been seen in the agarose gel electrophoresis of first-round PCR products. Interestingly, in two diarrheic samples the sequencing chromatograms showed that at specific positions alternative nucleotides could be found, suggesting that the two pigs were co-infected with more than one PKoV strains at the time of sampling. These firstround PCR products were cloned into the pMD-T-19 simple vector and the recombinant plasmid was transferred into E.coil DH5a competent cells. At least ten positive clones were sent for sequencing for each sample. 


\section{Statistical analysis}

The determined prevalence of $\mathrm{PKoV}$ in our study was analyzed statistically using Pearson's chi-square test in SPSS 21.0 to find out whether it was correlated with stool conditions and age of pig. Moreover, $p<0.05$ was considered statistically significant, while a $p$ value $<0.001$ indicated extremely marked statistical significance.

\section{Sequence and phylogenetic analysis}

The obtained nucleotide sequences and deduced amino acid sequences (excluding primer pair sequences) were compared with other known kobuviruses in the GenBank. Sequence similarity analysis was performed with the aligned nucleotide and amino acid sequences by the Clustal W method using the Megalign 7.2 program of Lasergene software (DNASTAR, Madison, USA). The Phylogenetic tree was constructed based on nucleotide alignments using the MEGA 5.0 program [48]. Nucleotide sequences were aligned using the ClustalW method and the phylogenetic tree was carried out by the neighbour joining method and Kimura 2-parameter model assuming uniform rates of change among sites, reliability value at each node was assessed by bootstrap method with 1,000 replications.

\section{Recombination analysis}

To detect possible recombination events among nucleotide alignment of the PKoV polyprotein sequences (1190 bp) from one pig, the Recombination Detection Program (RDP) was used to identify the possible parental sequences and recombinant strain [49]. The similarity between the putative parent strains and putative recombination could be showed in Simplot page using SIMPLOT version 3.5.1 [39]. Bootscan analysis was used to further investigate the potential recombination sites. We perfomed the software in the 2-parameter (Kimura) distance model and a sliding window of 200 nucleotides, step size of $20 \mathrm{bp}$.

\section{Competing interests}

The authors declare that they have no competing interests.

\section{Authors' contributions}

Conception and design of the experiments: LC, LZ, WZG, ZWX; Samples colletion: LC, YCZ, ZWX, WYY. Experimental work: LC; LZ; YCZ; WYY; Sequence and data analysis: LC; LZ; YCZ; manuscript preparation: LC. All authors have read and approved the final manuscript.

\section{Acknowledgements}

This study was supported by Sichuan Province Science and Technology Support Project. The Project name is as follows: Integration and industrialization model of modern swine industry chain key technology (2011FZ0065).

Received: 9 July 2013 Accepted: 10 September 2013 Published: 11 September 2013

\section{References}

1. Reuter G, Boldizsár Á, Pankovics P: Complete nucleotide and amino acid sequences and genetic organization of porcine kobuvirus, a member of a new species in the genus Kobuvirus, family Picornaviridae. Arch Virol 2009, 154:101-108.
2. Yamashita T, Ito M, Kabashima Y, Tsuzuki H, Fujiura A, Sakae K: Isolation and characterization of a new species of kobuvirus associated with cattle. J Gen Virol 2003, 84:3069-3077.

3. Yamashita T, Kobayashi S, Sakac K, Nakata S, Chiba S, Ishihara Y, Isomura S: Isolation of cytopathic small round viruses with $\mathrm{BS}-\mathrm{Cl}$ cells from patients with gastroenteritis. J Infect Dis 1991, 164:954-957.

4. Reuter G, Boldizsár Á, Kiss I, Pankovics P: Candidate new species of Kobuvirus in porcine hosts. Emerg Infect Dis 1968, 2008:14

5. Reuter G, Boros Á, Pankovics P, Egyed L: Kobuvirus in domestic sheep. Hungary. Emerg Infect Dis 2010, 16:869.

6. Reuter G, Nemes C, Boros Á, Kapusinszky B, Delwart E, Pankovics P: Porcine kobuvirus in wild boars (Sus scrofa). Arch Virol 2013, 158:281-282.

7. Kapoor A, Simmonds P, Dubovi EJ, Qaisar N, Henriquez JA, Medina J, Shields S, Lipkin WI: Characterization of a canine homolog of human Aichivirus. J Virol 2011, 85:11520-11525.

8. Lee M, Jeoung H, Lim J, Song J, Song D, An D: Kobuvirus in South Korean black goats. Virus genes 2012, 45:186-189.

9. Carmona-Vicente N, Buesa J, Brown PA, Merga JY, Darby AC, Stavisky J, Sadler L, Gaskell RM, Dawson S, Radford AD: Phylogeny and prevalence of kobuviruses in dogs and cats in the UK. Vet Microbiol 2013, 164:246-252.

10. Li L, Victoria JG, Wang C, Jones M, Fellers GM, Kunz TH, Delwart E: Bat guano virome: predominance of dietary viruses from insects and plants plus novel mammalian viruses. J Virol 2010, 84:6955-6965.

11. Phan TG, Kapusinszky B, Wang C, Rose RK, Lipton HL, Delwart EL: The fecal viral flora of wild rodents. PLoS pathogens 2011, 7:e1002218.

12. Yamashita T, Sakae K, Tsuzuki H, Suzuki Y, Ishikawa N, Takeda N, Miyamura T, Yamazaki S: Complete Nucleotide sequence and genetic organization of Aichi virus, a distinct member of the Picornaviridae associated with acute gastroenteritis in humans. J Virol 1998, 72:8408-8412.

13. Pham NTK, Khamrin P, Nguyen TA, Kanti DS, Phan TG, Okitsu S, Ushijima H: Isolation and molecular characterization of Aichi viruses from fecal specimens collected in Japan, Bangladesh, Thailand, and Vietnam. J Clin Microbiol 2007, 45:2287-2288.

14. Oh D, Silva PA, Hauroeder B, Diedrich S, Cardoso D, Schreier E: Molecular characterization of the first Aichi viruses isolated in Europe and in South America. Arch Virol 2006, 151:1199-1206.

15. Ambert-Balay K, Lorrot M, Bon F, Giraudon H, Kaplon J, Wolfer M, Lebon P, Gendrel D, Pothier P: Prevalence and genetic diversity of Aichi virus strains in stool samples from community and hospitalized patients. J Clin Microbiol 2008, 46:1252-1258.

16. Sdiri-Loulizi K, Gharbi-Khelifi H, De Rougemont A, Chouchane S, Sakly N, Ambert-Balay K, Hassine M, Guédiche MN, Aouni M, Pothier P: Acute infantile gastroenteritis associated with human enteric viruses in Tunisia. J Clin Microbiol 2008, 46:1349-1355.

17. Khamrin P, Maneekarn N, Peerakome S, Okitsu S, Mizuguchi M, Ushijima H: Bovine kobuviruses from cattle with diarrhea. Emerg Infect Dis 2008, 14:985.

18. Reuter G, Egyed L: Bovine kobuvirus in Europe. Emerg Infect Dis 2009, $15: 822$.

19. Barry AF, Ribeiro J, Alfieri AF, van der Poel WH, Alfieri AA: First detection of kobuvirus in farm animals in Brazil and the Netherlands. Infect Genet Evol 2011, 11:1811-1814.

20. Yu J, Jin M, Zhang Q, Li H, Li D, Xu Z, Li J, Cui S, Yang S, Liu N: Candidate porcine kobuvirus. China. Emerg Infect Dis 2009, 15:823.

21. Khamrin P, Maneekarn N, Kongkaew A, Kongkaew S, Okitsu S, Ushijima H: Porcine kobuvirus in piglets, Thailand. Emerg Infect Dis 2009, 15:2075-2076.

22. Halaihel N, Fuertes $H$, de Blas I, Gironés O: Kobuvirus and hepatitis-E virus infections in piglets: epidemiology and possible zoonosis. Virology 2011, 3:134.

23. Khamrin P, Maneekarn N, Hidaka S, Kishikawa S, Ushijima K, Okitsu S, Ushijima H: Molecular detection of kobuvirus sequences in stool samples collected from healthy pigs in Japan. Infect Genet Evol 2010, 10:950-954.

24. An D, Jeoung $H$, Jeong W, Lee HS, Park J, Kim B: Porcine kobuvirus from pig stool in Korea. Virus genes 2011, 42:208-211.

25. Verma H, Mor SK, Abdel-Glil MY, Goyal SM: Identification and molecular characterization of porcine kobuvirus in US swine. Virus genes 2013, 46:551-553

26. Dufkova L, Scigalkova I, Moutelikova R, Malenovska H, Prodelalova J: Genetic diversity of porcine sapoviruses, kobuviruses, and astroviruses in asymptomatic pigs: an emerging new sapovirus GIII genotype. Arch Virol 2012, 158:549-558. 
27. Reuter $G$, Kecskeméti S, Pankovics P: Evolution of porcine kobuvirus infection. Hungary. Emerg Infect Dis 2010, 16:696.

28. Okitsu S, Khamrin P, Thongprachum A, Hidaka S, Kongkaew S, Kongkaew A, Maneekarn N, Mizuguchi M, Hayakawa S, Ushijima H: Sequence analysis of porcine kobuvirus VP1 region detected in pigs in Japan and Thailand. Virus genes 2012, 44:253-257.

29. Park S, Kim H, Moon H, Song D, Rho S, Han J, Nguyen V, Park B: Molecular detection of porcine kobuviruses in pigs in Korea and their association with diarrhea. Arch Virol 2010, 155:1803-1811.

30. Yu J, Xu Z, Li B, Zhang Q, Cui S, Jin M, Duan Z: Analysis and characterization of the complete genome of a member of a new species of kobuvirus associated with swine. Arch Virol 2011, 156:747-751.

31. Wang C, Lan D, Hua X: Porcine kobuvirus from pig stool specimens in Shanghai, China. Virus genes 2011, 43:350-352.

32. Reuter G, Boros Á, Pankovics P: Kobuviruses-a comprehensive review. Rev Med Virol 2011, 21:32-41.

33. Shi D, Zhang S, Chen J, Shi H, Zhang X, Feng L: Molecular characterization of a porcine kobuvirus variant strain in China. Arch Virol 2013.

34. Padidam M, Sawyer S, Fauquet CM: Possible emergence of new geminiviruses by frequent recombination. Virology 1999, 265:218-225.

35. Martin DP, Posada D, Crandall KA, Williamson C: A modified bootscan algorithm for automated identification of recombinant sequences and recombination breakpoints. AIDS Res Hum Retrov 2005, 21:98-102.

36. Smith JM: Analyzing the mosaic structure of genes. J Mol Evol 1992, 34:126-129.

37. Posada D, Crandall KA: Evaluation of methods for detecting recombination from DNA sequences: computer simulations. P Natl Acad Sci 2001, 98:13757-13762.

38. Gibbs MJ, Armstrong JS, Gibbs AJ: Sister-scanning: a Monte Carlo procedure for assessing signals in recombinant sequences. Bioinformatics 2000, 16:573-582.

39. Lole KS, Bollinger RC, Paranjape RS, Gadkari D, Kulkarni SS, Novak NG, Ingersoll R, Sheppard HW, Ray SC: Full-length human immunodeficiency virus type 1 genomes from subtype C-infected seroconverters in India, with evidence of intersubtype recombination. J Virol 1999, 73:152-160.

40. Pham NTK, Trinh QD, Khamrin P, Nguyen TA, Dey SK, Phan TG, Hoang LP, Maneekarn N, Okitsu S, Mizuguchi M: Sequence analysis of the capsid gene of Aichi viruses detected from Japan, Bangladesh, Thailand, and Vietnam. J Med Virol 2008, 80:1222-1227.

41. Lau SK, Woo PC, Yip CC, Li KS, Fu CT, Huang Y, Chan K, Yuen K: Co-existence of multiple strains of two novel porcine bocaviruses in the same pig, a previously undescribed phenomenon in members of the family Parvoviridae, and evidence for inter-and intra-host genetic diversity and recombination. J Gen Virol 2011, 92:2047-2059.

42. Han $X$, Zhang W, Xue $Y$, Shao S: Sequence analysis reveals mosaic genome of Aichi virus. Virol J 2011, 8:390.

43. Lukashev AN: Recombination among picornaviruses. Rev Med Virol 2010, 20:327-337.

44. Park S, Kim H, Song D, Moon H, Park B: Molecular detection and genetic characterization of kobuviruses in fecal samples collected from diarrheic cattle in Korea. Infect Genet Evol 2011, 11:1178-1182.

45. Yamashita T, Sugiyama M, Tsuzuki H, Sakae K, Suzuki Y, Miyazaki Y: Application of a reverse transcription-PCR for identification and differentiation of Aichi virus, a new member of the Picornavirus family associated with gastroenteritis in humans. J Clin Microbiol 2000, 38:2955-2961

46. Le Guyader FS, Le Saux J, Ambert-Balay K, Krol J, Serais O, Parnaudeau S, Giraudon H, Delmas G, Pommepuy M, Pothier P: Aichi virus, norovirus, astrovirus, enterovirus, and rotavirus involved in clinical cases from a French oyster-related gastroenteritis outbreak. J Clin Microbiol 2008, 46:4011-4017

47. Cao W, Zheng H, Zhang K, Jin Y, Lv L, Yang F, Liu X: Complete genome sequence of the porcine kobuvirus variant CH/HNXX-4/2012.J Virol 2012, 86:11947.
48. Tamura K, Peterson D, Peterson N, Stecher G, Nei M, Kumar S: MEGA5: molecular evolutionary genetics analysis using maximum likelihood, evolutionary distance, and maximum parsimony methods. Mol Biol Evol 2011, 28:2731-2739.

49. Martin D, Rybicki E: RDP: detection of recombination amongst aligned sequences. Bioinformatics 2000, 16:562-563.

doi:10.1186/1743-422X-10-281

Cite this article as: Chen et al:: Molecular and phylogenetic analysis of the porcine kobuvirus VP1 region using infected pigs from Sichuan

Province, China. Virology Journal 2013 10:281.

\section{Submit your next manuscript to BioMed Central and take full advantage of:}

- Convenient online submission

- Thorough peer review

- No space constraints or color figure charges

- Immediate publication on acceptance

- Inclusion in PubMed, CAS, Scopus and Google Scholar

- Research which is freely available for redistribution

Submit your manuscript at www.biomedcentral.com/submit
C Biomed Central 